\title{
Angiotensin receptor blockers for the reduction of proteinuria in diabetic patients with overt nephropathy: results from the AMADEO study
}

\author{
Prasad Bichu' \\ Ravi Nistala' \\ Asma Khan ${ }^{2}$ \\ James R Sowers ${ }^{2}$ \\ Adam Whaley-Connell' \\ 'Divisions of Nephrology \\ and Endocrinology; ${ }^{2}$ Department \\ of Internal Medicine, University \\ of Missouri-Columbia School of \\ Medicine, Columbia Missouri, USA
}

Correspondence: Adam Whaley-Connell University of Missouri-Columbia School of Medicine, Department of Internal Medicine, Division of Nephrology CE4 I7, DC043.0 Five, Hospital Dr Columbia, MO 65212

Tel (573)882-7992

Fax (573)884-4820

Email whaleyconnella@health.missouri.edu

\begin{abstract}
Diabetic kidney disease is characterized by persistent albuminuria $(>300 \mathrm{mg} / \mathrm{dl}$ or $>200 \mu \mathrm{g} / \mathrm{min}$ ) that is confirmed on at least 2 occasions 3 to 6 months apart, with a progressive decline in the glomerular filtration rate (GFR), elevated arterial blood pressure, and an increased risk for cardiovascular morbidity and mortality. Diabetic kidney disease is the leading cause of end stage renal disease (ESRD) prompting investigators to evaluate mechanisms by which to slow disease progression. One such mechanism is to block the activity of angiotensin II at the receptor site and agents that follow this mechanism are referred to as angiotensin receptor blockers (ARB). There is sufficient clinical evidence to support that ARB have protective effects on kidney function in patients with diabetes and hypertension. However, in the past decade there have been few investigations comparing individual ARBs on renal outcomes. Telmisartan, a lipophilic ARB with a long half-life, has been hypothesized to have a greater anti-proteinuric effect when compared to the shorter acting losartan. Therefore, the A comparison of telMisartan versus losArtan in hypertensive type 2 DiabEtic patients with Overt nephropathy (AMADEO) trial sought to investigate renal and cardiovascular endpoints. In this review, we discuss the pathophysiology of diabetic kidney disease and implications of the AMADEO trial in the context of current understanding from recent outcome trials.
\end{abstract}

Keywords: diabetic kidney disease, hypertension, telmisartan, AMADEO

\section{Introduction}

Diabetic kidney disease (DKD) is the leading cause of end stage renal disease (ESRD) ${ }^{1}$ and is a multifactorial combination of hemodynamic and metabolic abnormalities that collectively contribute to kidney damage resulting in proteinuria and reductions in glomerular filtration rate (GFR). Recent data support that proteinuria is a surrogate maker for cardiovascular risk and reductions in proteinuria correlate with declines in cardiovascular morbidity and mortality. Thereby, interventions that target blood pressure control and proteinuria, specifically interruption of the renin-angiotensin system (RAS) with either angiotensin converting enzyme (ACE) inhibitors or angiotensin II receptor blockers (ARB), have been utilized in attenuating the progression of DKD. ${ }^{2}$ Among available ARBs, telmisartan has been reported to have a greater lipophilicity, longer half-life, and debatably the most consistent reductions in blood pressure. Therefore, investigators recently sought to compare telmisartan with losartan, which has less lipophilicity and a shorter duration of action, in patients who had overt DKD (urinary protein to creatinine ratio $\geq 700$ ) in the A comparison of telMisartan versus losArtan in hypertensive type 2 DiabEtic patients with Overt nephropathy (AMADEO) trial. Investigators reported that telmisartan was superior to losartan in reducing proteinuria in hypertensive patients with DKD with relatively similar reductions in blood pressures. Further, the authors proposed that the superiority of telmisartan could 
be due to its intrinsic peroxisome proliferator-activated receptor-gamma (PPAR- $\gamma$ ) agonist properties.

The incidence of DKD continues to increase in the US and globally. Understanding the mechanisms underlying the development of DKD is essential for establishing novel therapeutic strategies for the prevention or arrest of progressive disease. Herein, we will review some of these mechanisms as they relate to the AMADEO trial findings.

\section{Pathophysiology and markers of diabetic kidney disease}

Evidence suggests that up to $44 \%$ of patients with diabetes mellitus develop DKD. ${ }^{3}$ Development of DKD is associated with progressive functional and structural changes in the basic kidney unit, ie, the nephron and glomerulus, ${ }^{4}$ affected via hemodynamic and metabolic pathways. Hemodynamic and metabolic factors contribute equally towards the development of DKD, it is now clear that these processes are interlinked. Earlier stages of DKD include a hyperfiltration mechanism that occurs due to decreased resistance of both afferent and efferent arteriole. Afferent arteriole has greater decrease in resistance than its efferent counterpart. There is defective autoregulation of tone due to complex interaction of mediators including prostanoids, nitric oxide, reactive oxygen species (ROS), lipids, vascular endothelial growth factor (VEGF), transforming growth factor-beta 1 (TGF- $\beta 1$ ), high glucose and the RAAS, specifically angiotensin II (Ang II). These hemodynamic changes and the defect in autoregulation allow an increased filtration of albumin at the level of the glomerulus. It has been shown that proteinuria can occur as a result of molecular and structural abnormalities in the podocyte slit diaphragm within the glomerular epithelial cell. ${ }^{6,7}$ Ang II has been reported to be a primary mediator of loss of the slit-pore diaphragm. In addition to promoting glomerular nephrin depletion, Ang II also appears to have other actions that promote the development of proteinuria, including trophic effects on the kidney and increasing glomerular membrane pore size. This in turn promote structural changes like mesangial cell proliferation, thickening of basement membrane that further potentiate injury to podocytes. ${ }^{6}$ At the molecular level, hyperglycemia and proteins altered by high blood glucose such as Amadori products and advanced glycation end products (AGEs) are key players in the development of DKD. Evidence suggests that an increase in reactive oxygen species (ROS) formation induced by high glucose-mediated activation of the mitochondrial electron-transport chain is an early event in the development of diabetic complications. A variety of tissue growth factors and cytokines are then induced through complex signal transduction pathways involving protein kinase $\mathrm{C}$ (PKC), mitogen-activated protein kinases (MAPK), and the transcription factor NF- $\kappa$ B. High glucose, AGEs, and ROS act in concert to induce growth factors and cytokines. Particularly, tissue growth factors are important in the development of renal hypertrophy and accumulation of extracellular matrix components.

Activation of the renin-angiotensin-aldosterone system (RAAS) by hemodynamic changes, high glucose, mechanical stress, and proteinuria with an increase in local formation of Ang II contribute many of the pathophysiological changes associated with DKD (Figure 1). In fact, it has been shown that Ang II is involved in almost every pathophysiological process implicated in the development of DKD (hemodynamic changes, hypertrophy, extracellular matrix accumulation, growth factor/cytokine induction, ROS formation, podocyte damage, proteinuria, interstitial inflammation, adverse effects on the balance between the fibrinolytic and thrombotic mechanisms). ${ }^{8}$ Therefore, interruption of the RAAS via inhibition of Ang II is an essential part of every therapeutic regimen in managing the patient with DKD.

\section{Role of drugs blocking RAAS}

RAAS inhibition is the mainstay of therapy in preventing the progression of DKD. In addition to normalization of systemic and glomerular hypertension, it is now clear that inhibition of the RAAS at various levels by the Ang II antagonists (ACE inhibitors and ARBs) have several renoprotective effects, including anti-inflammatory and anti-fibrotic mechanisms. ${ }^{9}$ Addition of diuretics has been strongly recommended by KDOQI guidelines to achieve target blood pressures of $\leq 130 \mathrm{mmHg}$ in cases of recalcitrant hypertension in DKD patients. ${ }^{10}$ The role for aldosterone antagonist (spironolactone), renin antagonist (aliskiren) and statins in prevention of metabolic derangements consequent to RAAS overactivity in DKD is emerging. In whole animal models, experiments to tease out the non-hemodynamic renoprotective effects of the RAAS antagonists included transgenic rats with a human $\mathrm{AT}_{1}$ receptor $\left(\mathrm{AT}_{1} \mathrm{R}\right)$ gene which overexpressed $\mathrm{AT}_{1} \mathrm{R}^{11}{ }^{11}$ These rats developed significant albuminuria, podocyte effacement, progressive fibrosis, leading to focal segmental glomerulosclerosis (FSGS), which were independent of blood pressure and reversed by the blockade of Ang II. Aldosterone has been shown to cause kidney oxidative stress, inflammation, fibrosis, and sclerosis. Shibata et al demonstrated that aldosterone infusions and high-salt diet, when administered to uninephrectomized normotensive 


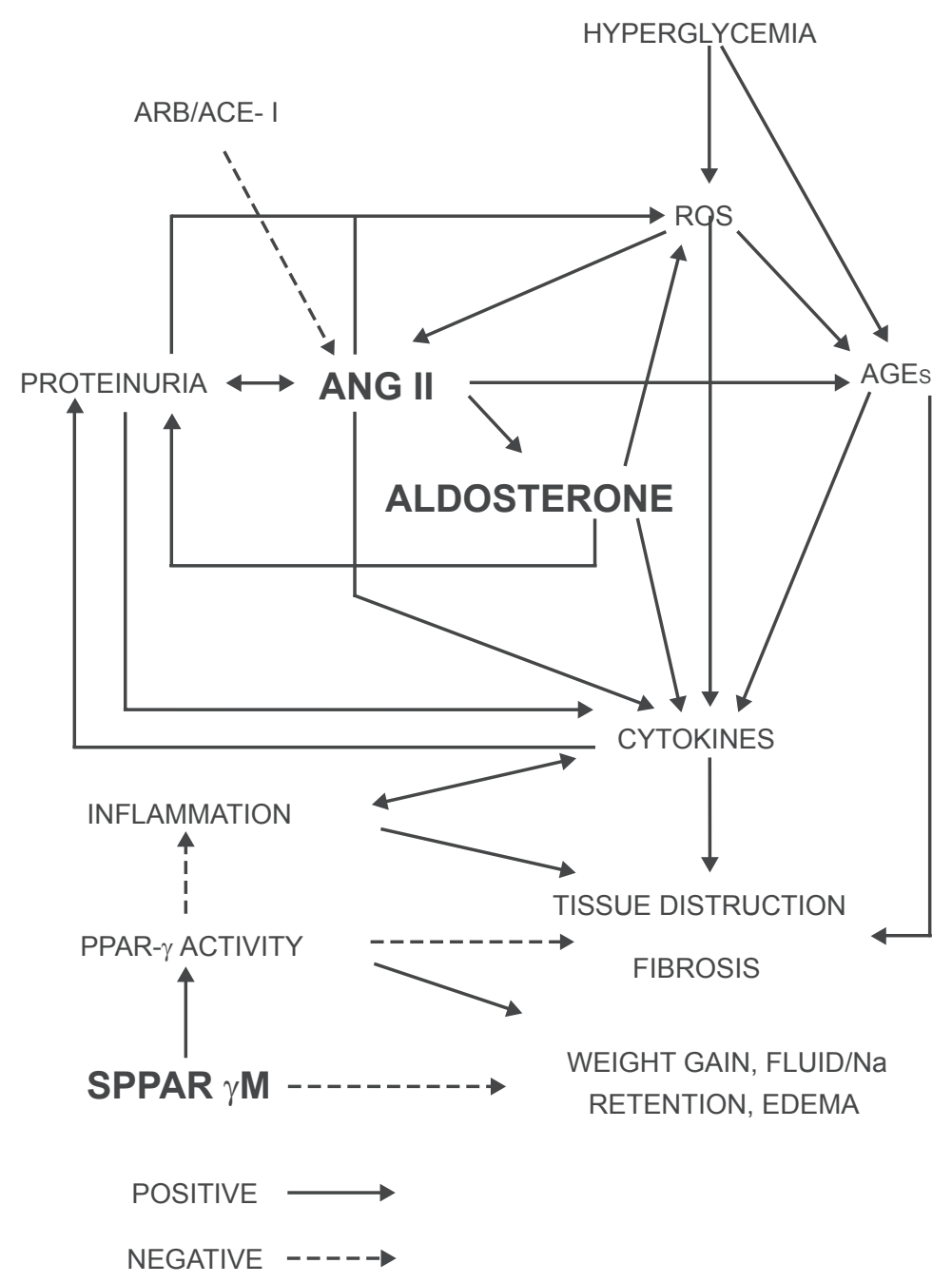

Figure I Schematic showing the current understanding of important players and pathways contributing to diabetic nephropathy/diabetic kidney disease. Point of action for telmisartan with dual ARB plus selective PPAR- $\gamma$ agonist properties is highlighted. Positive indicates action favoring DKD and negative indicates protection against DKD.

Sprague Dawley (SD) rats, led to glomerulosclerosis, hypertension, and kidney damage. ${ }^{12}$ Administration of the mineralocorticoid receptor (MR ) blocker (spironolactone) ameliorated and reversed the harmful effects of aldosterone. A recent study, Aliskiren in the EValuation of PrOteinuria In Diabetes (AVOID) Trial, showed that the addition of a renin inhibitor to an ARB in diabetic and hypertensive patients decreases proteinuria further when compared with an ARB alone. ${ }^{13}$ Statins have been proposed to have pleiotropic effects, actions independent of their cholesterol-lowering mechanism. These include decreased ROS generation via inhibition of NADPH oxidase and therefore have a role as renoprotective agent. ${ }^{14}$ Large randomized controlled trials designed to target DKD populations may be able to provide comprehensive answers as to the usefulness of these drugs.

Strong evidence points to the expression of all RAAS components in the kidneys, including the podocytes and tubular cells. ${ }^{15}$ High glucose stimulates expression of renin and angiotensinogen in mesangial and tubular cells. This stimulation results in an increase in local Ang II concentrations which may, in turn, through autocrine and paracrine pathways induce several cytokines and growth factors. Therefore blockade of the overexpressed RAAS will lead to renoprotection. Taking into account the many effects of the RAAS in the pathophysiology of DKD, early treatment with drugs interfering with the tissue effects of RAAS are a necessary prerequisite to prevent development and progression of DKD. ${ }^{16}$

\section{Lessons from clinical trials on RAAS-blockade}

Blockade of the RAAS is pivotal in the management of DKD as described above. Strong evidence favors the use of ACE inhibitors and ARBs in patients with type 2 diabetes 
Table I Recent clinical trials leading up to the AMADEO study

\begin{tabular}{|c|c|c|c|c|c|}
\hline Trial/year & Patient population & $\mathbf{N}$ & Treatment arms & Primary endpoint & Final outcome \\
\hline HOPE $^{19} 2001$ & $\begin{array}{l}\text { High-risk patients } \\
\text { without known diabetes }\end{array}$ & 5720 & Ramipril/placebo & $\begin{array}{l}\text { New onset overt } \\
\text { nephropathy }\end{array}$ & $\begin{array}{l}22 \% \text { Reduction in new onset overt } \\
\text { nephropathy (RR } 0.66 ; 95 \% \\
\text { Cl } 0.5 \text { I- } 0.85 ; \mathrm{p}<0.00 \mathrm{I})\end{array}$ \\
\hline IDNT $^{20} 200 \mathrm{I}$ & $\begin{array}{l}\text { Hypertension with } \\
\text { diabetic nephropathy }\end{array}$ & 1715 & $\begin{array}{l}\text { Irbesartan/amlodipine/ } \\
\text { placebo }\end{array}$ & $\begin{array}{l}\text { Composite of } \\
\text { development of ESRD, } \\
\text { doubling } \mathrm{Cr} \text {. }\end{array}$ & $\begin{array}{l}\text { Irbesartan significantly reduced } \\
\text { primary composite end point } \\
\text { by } 20 \% \text { compared to placebo } \\
\text { ( } p<0.02 \text { ) and by } 23 \% \text { compared to } \\
\text { amlodipine ( }<<0.006) \text {. }\end{array}$ \\
\hline IRMA222 200 I & Type 2 diabetes with MA & 590 & Irbesartan/placebo & $\begin{array}{l}\text { Time to onset of diabetic } \\
\text { nephropathy }\end{array}$ & $\begin{array}{l}\text { Irbesartan reduced risk of } \\
\text { primary end point }(\mathrm{HR} 0.30 \text {; } \\
95 \% \mathrm{Cl} 0.14-0.6 \mathrm{I} ; \mathrm{p}<0.00 \text { I for } \\
300 \mathrm{mg} \text { irbesartan; } \mathrm{HR} 0.61 ; 95 \% \\
\mathrm{Cl} 0.34-0.99 ; \mathrm{p}<0.08 \text { for } 150 \mathrm{mg} \\
\text { irbesartan. }\end{array}$ \\
\hline RENAAL ${ }^{23,24} 200$ I & $\begin{array}{l}\text { Type } 2 \text { diabetes with } \\
\text { nephropathy }\end{array}$ & 1513 & Losartan/placebo & $\begin{array}{l}\text { Composite of doubling of } \\
\mathrm{Cr} \text {, development of ESRD. }\end{array}$ & $\begin{array}{l}\text { Losartan significantly reduced the } \\
\text { composite end point by } 16 \% \\
\text { ( } p<0.02 \text { ), but not death. }\end{array}$ \\
\hline MARVAL $^{25} 2002$ & Type 2 diabetes with MA & 332 & Valsartan/amlodipine & $\begin{array}{l}\% \text { change in UAER from } \\
B L \text { to } 24 \mathrm{Wks} \text {. }\end{array}$ & $\begin{array}{l}\text { UAER at } 24 \text { wk was reduced by } \\
44 \% \text { with valsartan and } 8 \% \text { with } \\
\text { amlodipine }(p<0.00 \mathrm{I}) \text {; valsartan } \\
\text { significantly reversed MA to normal } \\
\text { albuminuria }\end{array}$ \\
\hline BENEDICT ${ }^{26,27} 2004$ & $\begin{array}{l}\text { Type } 2 \text { diabetes and } \\
\text { HTN but with normo- } \\
\text { albuminuria }\end{array}$ & 1204 & $\begin{array}{l}\text { Trandalopril/ } \\
\text { verapamil/placebo }\end{array}$ & $\begin{array}{l}\text { Development of } \\
\text { persistent MA }\end{array}$ & $\begin{array}{l}\text { For developing end point } \\
A F=0.39 \text { for trandalopril }+ \\
\text { verapamil vs placebo. } A F=0.44 \text { for } \\
\text { trandalopril vs placebo and } \\
A F=0.83 \text { with verapamil vs } \\
\text { placebo. }\end{array}$ \\
\hline DETAIL ${ }^{29} 2004$ & $\begin{array}{l}\text { Type } 2 \text { diabetes with } \\
\text { early nephropathy }\end{array}$ & 250 & Telmisartan/enalapril & $\begin{array}{l}\text { Change in the GFR } \\
\text { (determined by measuring } \\
\text { the plasma clearance of } \\
\text { iohexol) }\end{array}$ & $\begin{array}{l}\text { Change in the GFR was } \\
-17.9 \mathrm{~mL} / \mathrm{min} / 1.73 \mathrm{~m}^{2} \text { of body- } \\
\text { surface area with telmisartan, as } \\
\text { compared with }-14.9 \mathrm{~mL} / \mathrm{min} / 1.73 \mathrm{~m}^{2} \\
\text { with enalapril, for a treatment dif- } \\
\text { ference of }-3.0 \mathrm{~mL} / \mathrm{min} / 1.73 \mathrm{~m}^{2} \\
\left(95 \% \mathrm{Cl}-7.6-1.6 \mathrm{~mL} / \mathrm{min} / 1.73 \mathrm{~m}^{2}\right) \text {. }\end{array}$ \\
\hline TRENDY ${ }^{30} 2007$ & $\begin{array}{l}\text { Type } 2 \text { diabetes, } \mathrm{HTN} \text {, } \\
\text { GFR }>80 \mathrm{~mL} / \mathrm{min} \text {, and } \\
\text { normo- or micro- } \\
\text { albuminuria. }\end{array}$ & 96 & Telmisartan/ramipril & $\begin{array}{l}\text { Increase in renal plasma } \\
\text { flow (RPF) }\end{array}$ & $\begin{array}{l}\text { Telmisartan increased RPF from } \\
652.0 \pm 27.0 \text { to } 696.1 \pm \\
31.0 \mathrm{~mL} / \mathrm{min}(\mathrm{p}=0.047) \text {, whereas } \\
\text { ramipril produced no significant } \\
\text { changes in RPF. ( } r=0.47 \\
\mathrm{P}<0.00 \mathrm{I})\end{array}$ \\
\hline $\begin{array}{l}\text { INNOVATION }{ }^{32} \\
2007\end{array}$ & $\begin{array}{l}\text { Type } 2 \text { diabetes and } \\
\text { UACR } 100-300 \mathrm{mg} / \mathrm{g}, \\
\mathrm{Cr}<1.5 \mathrm{mg} / \mathrm{dl} \text { (men) } \\
\text { and }<1.3 \mathrm{mg} / \mathrm{dl} \\
\text { (women). }\end{array}$ & 527 & $\begin{array}{l}\text { Telmisartan } \\
(80 / 40 \text { mg)/placebo }\end{array}$ & $\begin{array}{l}\text { Transition rate incipient } \\
\text { to overt Nephropathy, } \\
\text { UACR }>300 \mathrm{mg} / \mathrm{g} \text {, and } \\
\text { increase } \geq 30 \% \text { from } \\
\text { baseline at } 2 \text { consecutive } \\
\text { 4-week visits. }\end{array}$ & $\begin{array}{l}\text { Transition rates to overt } \\
\text { nephropathy were } 16.7 \% \text { with } \\
80 \text { mg telmisartan }(n=168), 22.6 \% \\
\text { with } 40 \text { mg telmisartan } \\
(n=172) \text {, and } 49.9 \% \text { with placebo } \\
(n=174) \text { (both telmisartan doses/ } \\
\text { placebo, } p<0.000 \text { I). }\end{array}$ \\
\hline VIVALDI $^{31} 2008$ & $\begin{array}{l}\text { HTN SBP/ } \\
\text { DBP }>130 / 80 \mathrm{mmHg} \\
\text { patients with type } 2 \\
\text { diabetes, proteinuria } \\
(\geq 900 \mathrm{mg} / 24 \mathrm{~h}) \text { and } \mathrm{Cr} \\
(\leq 3.0 \mathrm{mg} / \mathrm{dL})\end{array}$ & 885 & Telmisartan/valsartan & $\begin{array}{l}\text { Change from } \mathrm{BL} \text { of } 24 \mathrm{~h} \\
\text { proteinuria. }\end{array}$ & $\begin{array}{l}\text { Comparable reduction in } 24 \mathrm{~h} \\
\text { urinary protein excretion rates. } \\
\text { Geometric mean reduction } \\
\text { ( } 95 \% \text { confidence interval) } \\
\text { telmisartan, 33\% (27\%-39\%); } \\
\text { valsartan, } 33 \%(27 \%-38 \%) \text {. }\end{array}$ \\
\hline
\end{tabular}

(Continued) 
Table I (Continued)

\begin{tabular}{|c|c|c|c|c|c|}
\hline Trial/year & Patient population & $\mathbf{N}$ & Treatment arms & Primary endpoint & Final outcome \\
\hline ONTARGET ${ }^{28} 2008$ & $\begin{array}{l}55 \text { years or older with } \\
\text { established atheroscle- } \\
\text { rotic vascular disease } \\
\text { or with diabetes with } \\
\text { end-organ damage }\end{array}$ & 8542 & $\begin{array}{l}\text { Telmisartan/ramipril/ } \\
\text { telmisartan + ramipril }\end{array}$ & $\begin{array}{l}\text { Composite of dialysis, } \\
\text { doubling of } C R \text {, and death }\end{array}$ & $\begin{array}{l}\text { Composite primary outcome } \\
\text { was similar for telmisartan (I I } 47 \\
\text { [I3.4\%]) and ramipril (I I } 50 \text { [I3.5\%]; } \\
\text { HR I.00, } 95 \% \mathrm{CI} 0.92-\mathrm{I} .09) \text {, but } \\
\text { was increased with combination } \\
\text { therapy (I233 [I4.5\%]; HR I.09, } \\
\text { I.0I-I.I8, P = 0.037). }\end{array}$ \\
\hline
\end{tabular}

Abbreviations: $\mathrm{BL}$, baseline; $\mathrm{Cl}$, confidence interval; $\mathrm{RR}$, relative risk; $\mathrm{HR}$, hazard ratio; $\mathrm{Cr}$, serum creatinine; $\mathrm{CV}$, cardiovascular; $\mathrm{HF}$, heart failure; $\mathrm{CAD}$, coronary artery disease; MA, microalbuminuria; ESRD, end stage renal disease; RPF, renal plasma flow; MI, myocardial infarction; N, number of patients enrolled; UAER, urine albumin excretion; wk, weeks; GFR, glomerular filteration rate; NIDDM, non-insulin-dependent diabetes mellitus; HOPE, Heart Outcomes Prevention Evaluation study; IRMA, IRbesartan in patients with type 2 diabetes with MicroAlbuminuria study; IDNT, Irbesartan Diabetic Nephropathy Trial; LIFE, Losartan Intervention For Endpoint reduction in hypertension Study; MARVAL, MicroAlbuminuria Reduction with VALsartan trial; RENAAL, Reduction of Endpoints in NIDDM with the Angiotensin II Antagonist; Losartan; BENEDICT, Bergamo Nephrologic Diabetes Complications Trial;TRENDY,Telmisartan versus Ramipril in renal Endothelial Dysfunction; INNOVATION, INcipieNt to OVert:Angiotensin II receptor blocker, Telmisartan, Investigation On type 2 diabetic Nephropathy;VIVALDI, inVestlgate the efficacy of telmlsartan versus VALsartan in hypertensive type 2 Dlabetic patients with overt nephropathy; ONTARGET, ONgoing Telmisartan Alone and in combination with Ramipril Global Endpoint Trial.

and overt nephropathy. ${ }^{17}$ Current management consensus statements from the National Kidney Foundation (NKF)/ Kidney Disease Outcomes Quality Initiative (KDOQI), ${ }^{10}$ American Diabetes Association (ADA), ${ }^{1}$ and Joint National Committee (JNC) VII ${ }^{18}$ advocate the use of ARBs for management of patients with hypertension and DKD, even in those with advanced stages of nephropathy as well as in those with microalbuminuria. ARBs have been shown to exert their beneficial effect by blood pressure reduction, improving endothelial dysfunction and reducing oxidative stress. ${ }^{17}$

Data from the Heart Outcomes Prevention Evaluation (HOPE) Study evaluated microalbuminuria as a progressive manifestation of overt type nephropathy in patients with type 2 diabetes as a secondary endpoint. ${ }^{19}$ Ramipril was shown to reduce the onset of overt nephropathy by $22 \%$. Similar observations were reported in the Irbesartan type II Diabetic Nephropathy Trial (IDNT), irbesartan was superior to both placebo and amlodipine in improving time to the primary endpoint, which was the composite of doubling of baseline serum creatinine and development of ESRD. ${ }^{20}$ Interestingly, the benefits of irbesartan were seen with similar reductions in blood pressure when compared to amlodipine, revealing non-hemodynamic effects of ARBs. However, this trial did not include ACE inhibition in its treatment arms. Another caveat that was borne out of post-hoc analyses was that initial changes in proteinuria were not independent predictors of long-term renal outcomes, but were dependent on specific treatment arms (in this case irbesartan). This effect was later tested in the AMADEO trial. Analysis of IDNT showed that over a follow up period of 2.6 years there was a 2.2 times increase in risk of doubling serum creatinine or ESRD in patients with systolic blood pressure $(\mathrm{SBP})>149 \mathrm{mmHg}$ compared with those with $\mathrm{SBP}<143 \mathrm{mmHg}$ regardless of the intervention used for treatment of blood pressure. Among the patients achieving comparable reduction in SBP, the incidence of renal endpoints was lower in patients treated with irbesartan compared to amlodipine. ${ }^{21}$

The Irbesartan in Patients with Type 2 Diabetes and Microalbuminuria Study (IRMA) further strengthened the results of IDNT by showing that irbesartan has a dosedependent improvement in time to onset of DKD. ${ }^{22}$ After a follow up of 2 years, it was found that only 5.2\% patients treated with irbesartan $300 \mathrm{mg}$ progressed to overt nephropathy as opposed to $9.7 \%$ of those receiving irbesartan $150 \mathrm{mg}$ and $14.9 \%$ of those receiving placebo. In fact, the IRMA study group hypothesized that the renoprotective effect of irbesartan was not fully evident in their original study due to dose limitations and they demonstrated even greater renal protection with $900 \mathrm{mg}$ of irbesartan and minimal increase in side effects (IRMA-2). The Reduction of Endpoints in NIDDM with the Angiotensin II Antagonist Losartan Study (RENAAL) study was similar to the IDNT and IRMA studies and demonstrated delayed time to onset of renal dysfunction in the losartan treated group. ${ }^{23}$ Post hoc analyses of proteinuria as secondary endpoint showed that early response to losartan therapy is an important predictor of long term renal protection. ${ }^{24}$ Both baseline and residual (6 month) albuminuria were linearly correlated with renal outcomes. The authors recommended reduction in albuminuria to the lowest achievable level as the optimum goal for therapy.

MicroAlbuminuria Reduction With VALsartan (MARVAL) Study targeted urine microalbumin excretion (UAER) as the primary endpoint and demonstrated reduction in albuminuria to $56 \%$ of its baseline in both normotensive and hypertensive 
type 2 diabetics after 6 months of intention to treat therapy. ${ }^{25}$ Importantly, the improvement in albuminuria was independent of blood pressure, as the amlodipine treatment arm achieved similar reductions in blood pressure, once again demonstrating non-hemodynamic effects of ARBs in modulating pathophysiology of DKD.

The Bergamo Nephrologic Diabetes Complications Trial (BENEDICT) compared the efficacy of ACE inhibitor trandalopril versus non-dihydropyridine calcium channel blocker verapamil versus trandalopril alone versus verapamil alone versus placebo in delaying the incidence of microalbuminuria in type 2 diabetics. ${ }^{26,27}$ The trandalopril containing arms demonstrated significant delay in the development of microalbuminuria. Interestingly, ONTARGET evaluated the use of ACE inhibitor in prevention of early chronic kidney disease. ${ }^{28}$ RAAS control with ACE inhibitor has been shown to prevent the emergence of persistent microalbuminuria in patients with type 2 diabetes and apparently normal urinary albumin levels ( $<20 \mu \mathrm{g} / \mathrm{min})$.

The Diabetics Exposed to Telmisartan and EnalaprIL (DETAIL) study was among the first studies to compare the efficacy of long-acting telmisartan with ACE inhibitor enalapril. ${ }^{29}$ Although there was an initial advantage in slowing down the decline in GFR with telmisartan, end of trial analyses could only demonstrate non-inferiority over enalapril. Based on the findings of DETAIL, it may be argued that a more aggressive approach to renoprotection may be required in the long term. ${ }^{16}$ The recently published Telmisartan versus Ramipril in renal Endothelial DYsfunction (TRENDY) study provided the first head-to-head comparison of an ARB and an ACE inhibitor on renal endothelial function. ${ }^{30}$ TRENDY was performed in 96 patients with type 2 diabetes who had mild-to-moderate hypertension (seated SBP/diastolic blood pressure [DBP] 140 to $180 / 90$ to $110 \mathrm{~mm} \mathrm{Hg}$ ), normo- or microalbuminuria, and GFR $>80 \mathrm{~mL} / \mathrm{minute} / 1.73 \mathrm{~m}^{2}$. Patients were randomized to either telmisartan $40 \mathrm{mg}$ or ramipril $5 \mathrm{mg}$ for 3 weeks, followed by telmisartan $80 \mathrm{mg}$ or ramipril $10 \mathrm{mg}$ for 6 weeks. Both telmisartan and ramipril improved nitric oxide activity (a measure of endothelial function), with a trend toward superiority of telmisartan. There was also a significant decrease in urinary albumin excretion from 9.0 to $7.3 \mathrm{mg} / 24$ hours with telmisartan ( $\mathrm{p}=0.022$ ), whereas the change from baseline with ramipril was not significant.

In the study to inVestIgate the efficacy of telmIsartan versus VALsartan in hypertensive type 2 DIabetic patients with overt nephropathy (VIVALDI), both telmisartan and valsartan improved proteinuria by $33 \%$ at the end of 1 year. ${ }^{31}$
However, the benefits from telmisartan were not significantly greater than valsartan in this intention to treat analysis. The authors did note that patients in the valsartan treatment arm tended to receive additional antihypertensives in a greater proportion than the telmisartan group most probably due to the shorter half-life of the former drug. ${ }^{31}$ Moreover, proteinuria measurements were based on 24-hour urine protein collections. The INcipieNt to OVert: Angiotensin II receptor blocker, Telmisartan, Investigation On type 2 diabetic Nephropathy (INNOVATION) trial showed that telmisartan is able to prevent the transition to overt renal disease in Japanese patients after a mean follow-up of 1.3 years. ${ }^{32}$ The relative risk of transition to overt nephropathy was reduced by $66 \%$ and $55 \%$, respectively, with telmisartan $80 \mathrm{mg}$ and telmisartan $40 \mathrm{mg}$ compared with placebo in the overall patient population. Thus, for every 3 patients treated, telmisartan $80 \mathrm{mg}$ prevented 1 transition to overt nephropathy over the course of approximately 1 year. The renoprotective benefit of telmisartan was also apparent in patients who were normotensive at baseline, which suggests that there is a blood pressure-independent effect. In addition, INNOVATION showed treatment of patients with telmisartan could bring about regression of incipient disease, with $21.2 \%$ and $12.8 \%$ of patients in the telmisartan $80 \mathrm{mg}$ and $40 \mathrm{mg}$ arms respectively, becoming normoalbuminuric compared with $1.2 \%$ of patients receiving placebo (both doses $\mathrm{p}<0.001$ ). ${ }^{32}$ Interestingly, both the DROP trial and the IRMA-2 substudy demonstrated a greater anti-proteinuric effect with ultra-high doses of ARBs while not significantly achieving any further lowering in blood pressure. ${ }^{33,34,35}$

The recently published ONgoing Telmisartan Alone and in combination with Ramipril Global Endpoint Trial (ONTARGET trial) compared the renal effects of ramipril (an ACE inhibitor), telmisartan (an ARB), and their combination in patients aged 55 years or older with established atherosclerotic vascular disease or diabetes with end-organ damage. ${ }^{28}$ The number of events for the composite primary outcome dialysis, doubling of serum creatinine, and death were similar for telmisartan and ramipril but was increased with combination therapy. The secondary renal outcome, dialysis or doubling of serum creatinine, was similar for telmisartan and ramipril and more frequent with combination therapy. The trial authors concluded that in people at high vascular risk, telmisartan's effects on major renal outcomes are similar and non-inferior to those of ramipril. Although combination therapy reduced proteinuria to a greater extent than monotherapy, the net effect on renal outcomes was opposite. The take-home message was that, proteinuria by 
itself cannot be taken as a definitive marker of improved renal function, and that the benefits of any treatment, including combination blockade of the RAS on major renal outcomes, remain to be elucidated.

\section{Rationale for AMADEO trial}

Substantial evidence has accumulated over the last decade in favor of using RAAS inhibitors for slowing down the progression and onset of DKD. Use of ARB and ACE inhibition is clearly superior to the use of non-RAAS blood pressure control medications in ameliorating renal damage at similar levels of blood pressure control. ${ }^{20}$ This may be due to the non-hemodynamic and metabolic improvements in the cardiovascular system including better endothelial function, reduced oxidative stress, decrease in inflammation and fibrosis. Evidence has emerged demonstrating that a $>30 \%$ reduction in proteinuria at 6 months to 1 year following initiation of treatment was associated with slower progression of DKD and a reduction in the incidence of cardiovascular events, independent of reductions in blood pressures. The ARBs have been shown to be non-inferior to ACE inhibitors in achieving blood pressure control and reductions in proteinuria, often leading to interchangeable regimens based on these drugs depending on the tolerability by patients.

Telmisartan, an ARB with high lipophilicity, a high level of angiotensin II type-1 ( $\left.\mathrm{AT}_{1}\right)$ receptor $\left(\mathrm{AT}_{1} \mathrm{R}\right)$ binding and a long half-life is currently FDA approved for the treatment of hypertension but is not indicated yet for the treatment of proteinuria in patients with diabetes. Instead, losartan is currently approved as a first-line treatment for DKD. Telmisartan has been reported to achieve smoother blood pressure control with fewer side effects when compared to other ARBs. In addition, animal experiments have demonstrated other potential mechanisms for its beneficial effects including PPAR- $\gamma$ agonist properties. ${ }^{36}$ All of these properties together may make telmisartan an ideal drug to achieve the target of $>30 \%$ reduction in proteinuria ultimately resulting in a slower progression to kidney failure.

\section{Pharmacology of telmisartan}

Telmisartan is a potent, long-lasting, non-peptide antagonist of the $\mathrm{AT}_{1} \mathrm{R}$. It selectively and insurmountably inhibits stimulation of the $\mathrm{AT}_{1}$ receptor by angiotensin II without affecting other receptor systems involved in cardiovascular regulation. Very high lipophilicity, a unique feature of telmisartan, coupled with a high volume of distribution; indicate that the compound offers a clinically important advantage of good tissue penetration (Table 2). Due to its physicochemical properties, telmisartan shows excellent oral absorption and tissue penetration. ${ }^{38}$

\section{Affinity for AT, receptor}

Studies have demonstrated that telmisartan has the strongest binding affinity to $\mathrm{AT}_{1}$ receptor among various $\mathrm{ARBs}$ (Table 2). The rank order of affinity is in the following order; telmisartan $>$ olmesartan $>$ candesartan $>$ EXP3174 $>$ valsartan $>$ losartan. ${ }^{39}$ The findings of AMADEO suggest that telmisartan may have long-lasting blood pressure-lowering effects and superior cardioprotective properties in patients with hypertension due to its strong $\mathrm{AT}_{1}$ receptor antagonistic ability.

\section{Pharmacokinetics}

Telmisartan is not a pro-drug and has a longer terminal elimination half-life than other commercially available sartans ( 24 hours), making it suitable for once-daily dosing. The compound is not metabolized by cytochrome P450 isoenzymes and has a low risk for P450-based drug interactions. ${ }^{37,38} \mathrm{~A}$ relevant fact to be noted is that unlike other ARBs, where up to $50 \%$ of the dose is excreted by the kidney, only $1 \%$ of a telmisartan dose in excreted by the kidney. Therefore renal impairment is unlikely to affect the pharmacokinetics of telmisartan. ${ }^{37}$ Telmisartan has a pharmacokinetic profile that allows differentiating it from other angiotensin receptor blockers; long duration of action (mean terminal half-life of 24 hours, the longest in its class) and high tissue penetration (illustrated by the

Table 2 Pharmacokinetics of ARBs ${ }^{37,38,39}$

\begin{tabular}{llllll}
\hline Drug & Bioavailability (\%) & Half-life (hours) & Lipophilicity (log P) & Protein binding (\%) & AT, receptor affinity \\
\hline Losartan & 33 & $2(6-9)$ & -2.45 & 98.7 & $20 \mathrm{nmol} / \mathrm{L}$ \\
Valsartan & 25 & 9 & -0.95 & 95 & $1.3 \mathrm{nmol} / \mathrm{L}$ \\
Irbesartan & 70 & $1 \mathrm{I}-15$ & +1.48 & 90 & $2.7 \mathrm{nmol} / \mathrm{L}$ \\
Telmisartan & 43 & 24 & +1.48 & 799 & $3.7 \mathrm{nmol} / \mathrm{L}$ \\
Eprosartan & 15 & $5-7$ & - & 98 & $1.4-3.9 \mathrm{nmol} / \mathrm{L}$ \\
\hline
\end{tabular}

aThe logarithm of the ratio of the concentrations of the un-ionized solute in the solvents is called log P (partition coefficient). 
highest volume of distribution in its class), and high affinity for angiotensin receptor.

\section{PPAR- $\gamma$ agonist effect of telmisartan}

Telmisartan is the only ARB which acts as a partial agonist of PPAR- $\gamma$. PPAR- $\gamma$ is a ligand activated transcription factor that regulates cell growth, inflammation, lipid metabolism and insulin sensitivity. It has been successfully shown that PPAR- $\gamma$ agonists limit high glucose-induced inflammation in proximal tubular cells (PTC). ${ }^{40}$ PPAR $-\gamma$ agonists also exert anti-fibrotic effects in human proximal tubular cells under high glucose conditions by attenuating the increase in AP-1, TGF- $\beta 1$ and downstream production of the extracellular matrix protein, fibronectin. PPAR- $\gamma$ agonists can improve insulin sensitivity, reduce triglyceride levels and decrease the risk of atherosclerosis.

A study examined the ability of different ARBs to activate PPAR- $\gamma$ in a cell-based transient transfection assay (Figure 2). This assay was designed to eliminate interference from endogenous nuclear receptors. In the results shown here, each ARB was used at a concentration of $10 \mathrm{mmol} / \mathrm{L}$. Telmisartan was the only ARB to show strong (27-fold) activation, although irbesartan also showed a slight activation (2- to 3-fold). By comparison, full PPAR- $\gamma$ agonists show $\sim 140$-fold activation in this assay. Importantly,

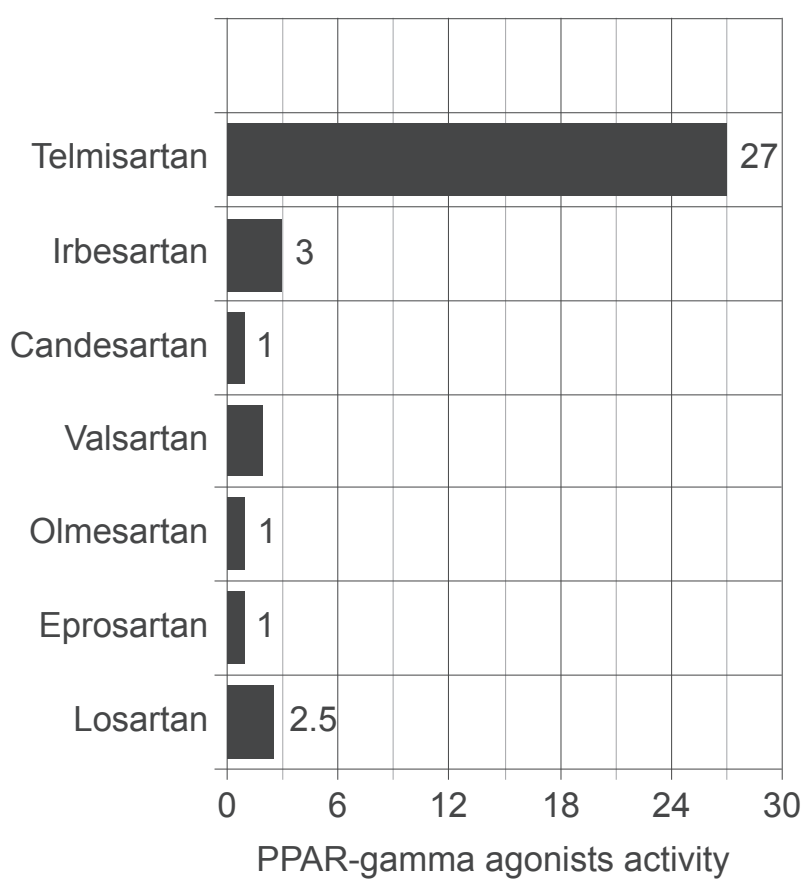

Figure 2 Inherent PPAR- $\gamma$ agonist activity of various ARBs. Importantly, full PPAR- $\gamma$ agonists, ie, thiazolidinediones typically have agonist activity in the 150 to 200 range. Drawn from data of. ${ }^{36}$ telmisartan was also the only ARB that activated PPAR- $\gamma$ when tested at lower concentrations that can be achieved physiologically $(1-5 \mathrm{mmol} / \mathrm{L})$. Telmisartan therefore acts as a partial agonist of PPAR- $\gamma \cdot{ }^{36}$

There have been reports of sodium and fluid retention associated with full PPAR- $\gamma$ agonist activity. Evidence suggests that PPAR- $\gamma$ is highly expressed in the medullary collecting ducts with lower expression levels in glomeruli, proximal tubules and microvasculature and is a major site for increased fluid reabsorption in response to PPAR- $\gamma$ agonist activity. ${ }^{41,42}$ In these collecting ducts, PPAR- $\gamma$ activation increases sodium re-absorption through epithelial sodium channel $(\mathrm{ENaC})$ dependent and independent mechanisms ( $\mathrm{Na}^{+}-\mathrm{K}^{+}$-ATPase system). Guan et al showed that showed that mice treated with thiazolidinediones (TZDs, full PPAR- $\gamma$ agonists), experience early weight gain from increased total body water. ${ }^{41}$ Weight gain was blocked by the collecting duct-specific diuretic amiloride and was also prevented by deletion of PPAR- $\gamma$ from the collecting duct, using PPAR- $\gamma$ (flox/flox) mice. Moreover, treating cultured medullary collecting ducts with TZD increased amiloridesensitive sodium absorption and mRNA expression of ENaC- $\gamma$ isoform through a PPAR- $\gamma$ dependent pathway. Furthermore, in the blood vessels of adipose tissues, PPAR- $\gamma$ ligands activate protein kinase $\mathrm{C}$ (PKC), vascular endothelial growth factor (VEGF), and nitric oxide (NO), which together lead to increased endothelial permeability. Thus increased renal sodium retention at the level of the collecting duct in conjunction with increased vascular permeability may cause edema development and account for the side effects of drugs with full PPAR- $\gamma$ agonist activity.

The above-mentioned adverse effects have caused high attrition rates which led to the need for the discovery and characterization of alternative PPAR modulators that would retain the beneficial properties of these drugs while avoiding the cardiovascular side effects. These are called the Selective Modulators of PPAR- $\gamma$ activity (SPPAR $\gamma M) .{ }^{43,46}$ PPAR- $\gamma$ receptor is a multivalent receptor whose ligand binding domain can accommodate different ligands (full agonist, partial agonist, or SPPAR $\gamma \mathrm{M}$ ) and is capable of inducing distinct receptor combinations leading to selective gene expression. Each ligand-receptor complex assumes a somewhat different three-dimensional conformation, leading to unique and differential interactions with co-factors, histones, and other transcription factors. Consequently, each PPAR- $\gamma$ ligand-receptor complex leads to a differential, but overlapping, pattern of gene expression and ultimately differential biological responses. ${ }^{43,46}$ Telmisartan has been shown to be a 
partial PPAR- $\gamma$ agonist and may have SPPAR $\gamma \mathrm{Ms}$ properties as well. ${ }^{43}$ Schupp et al used diet-induced obese mouse models and analysis of PPAR- $\gamma$ protein conformation using protease protection to show that telmisartan directly interacts with the receptor, producing distinct conformational change compared with a TZD. ${ }^{43}$ Telmisartan significantly reduced fasting plasma insulin and glucose levels and improved glucose tolerance and insulin sensitivity and caused significantly less weight gain compared with mice treated with pioglitazone. In vivo studies therefore suggest that Telmisartan has the beneficial properties of PPAR- $\gamma$ agonists sans the side effects including sodium retention, peripheral edema and weight gain exhibited by some of the other full PPAR- $\gamma$ agonists. The safety profile may imply an important use for drugs like telmisartan in the treatment of metabolic syndrome. ${ }^{45}$

\section{AMADEO trial ${ }^{2}$}

In the AMADEO trial, diabetic patients fulfilling the inclusion criteria were prospectively randomized (double-blind, double-dummy, forced titration) to receive telmisartan $(n=419)$ or losartan $(n=441)$, following a 2-month drug-free washout period. Patients were treated for 52 weeks in a forcedtitration dosing, reaching maximum doses of $100 \mathrm{mg} /$ day losartan and $80 \mathrm{mg} /$ day telmisartan. Add on therapy with other antihypertensive medications were provided in case SBP remained $\geq 130 \mathrm{mmHg}$ and $\mathrm{DBP} \geq 80 \mathrm{mmHg}$ after forced titration of the study drugs. The two study arms did not have significant differences in the use of adjunctive therapy. A drug-free follow up group included 346 patients for 2 months after the trial was concluded.

After a 4-week run-in period, 860 hypertensive patients (BP $>130 / 80 \mathrm{mmHg}$ ) with type 2 diabetes and overt nephropathy (UPC $\geq 700 \mathrm{mg} / \mathrm{g}$ ) were randomized to one of two treatment arms: telmisartan $40 \mathrm{mg}$ or losartan $50 \mathrm{mg}$. After 2 weeks, the doses were increased to $80 \mathrm{mg}$

Table 3A Primary endpoint of AMADEO trial ${ }^{2}$

\begin{tabular}{llll}
\hline Primary endpoint & Telmisartan & Losartan & P value \\
\hline Urine protein: creatinine & 0.71 & 0.80 & 0.0284 \\
\hline
\end{tabular}

and $100 \mathrm{mg}$, respectively. If blood-pressure control was not at goal, $25 \mathrm{mg}$ of hydrochlorothiazide (HCTZ) was added, and if blood pressure was still resistant, clinicians were free to add a calcium-channel blocker. Baseline characteristics between the two treatment arms were not statistically different. After one year of therapy with the two ARBs, telmisartan provided greater reductions in the amount of protein in the urine (Table 3A), a finding not attributed to blood-pressure control, as reductions in SBP and DPB were similar in both treatment arms. As per study protocol, after a 2-month period at study completion in which both drugs were stopped, investigators reported a sustained and persistent antiproteinuric effect with the novel ARB, telmisartan. The persistent effect of telmisartan was surprising and the authors suggest that this beneficial effect could be explained by differences in receptor bindings, duration of action, or lipophilicity between the two drugs used in the trial. The difference in secondary end points of serum creatinine, eGFR, serum aldosterone and CRP failed to reach significance (Table 3B). Serum aldosterone tended to decrease to a greater extent in the telmisartan group, however statistical significance could not be attained $(\mathrm{p}=0.07)$.

\section{Does AMADEO trial unequivocally prove superiority of telmisartan?}

Based on the AMADEO trial, a telmisartan-based regimen provides for robust anti-proteinuric effect in type 2 diabetic patients with hypertension and overt nephropathy. This anti-proteinuric effect is greater than a losartan-based regimen at levels of blood pressure that were not significantly different between groups and is attributed to greater lipophilicity and longer duration of action of this drug. Based on available trial data, this difference in anti-proteinuric effect may translate into better cardiovascular and renal outcomes.

The contribution of confounding factors to telmisartan's superiority over losartan remain unclear, especially telmisartan's partial PPAR- $\gamma$ agonist effect. As discussed above, PPAR- $\gamma$ agonists limit high glucose-induced inflammation in proximal tubular cells, exert anti-fibrotic effects in the same cells by attenuating the increase in AP-1, TGF- $\beta 1$

Table 3B Secondary endpoint of AMADEO trial ${ }^{2}$

\begin{tabular}{llll}
\hline Secondary endpoint & Telmisartan $\mathbf{8 0} \mathbf{~ m g}$ & Losartan I00 $\mathbf{~ m g}$ & P value \\
\hline Serum creatinine & $15 \%(12 \%$ to $18 \%)$ & $15 \%(12 \%$ to I8\%) & 0.895 \\
eGFR & $-6.49(-7.56$ to 5.42$)$ & $-6.50(-7.56 \%$ to -5.43$)$ & $0.99 \mid 3$ \\
Serum aldosterone & $-23(-29 \%$ to $18 \%)$ & $-17 \%(-23 \%$ to $-1 \mid \%)$ & 0.0746 \\
CRP & $-6(-15 \%$ to $4 \%)$ & $1 \%(-9 \%$ to $13 \%)$ & 0.277 \\
\hline
\end{tabular}

Abbreviations: CRP, C-reative protein; eGFR, estimated glomerular filtration rate. 
and the downstream production of the extracellular matrix protein fibronectin and have been shown to improve insulin sensitivity, reduce triglyceride levels and decrease the risk for atherosclerosis. This has been acknowledged by the trial authors as an explanation for telmisartan's mechanism of action in vitro and further studies need to be done to demonstrate the action in vivo. Another issue regarding the differences in proteinuria between the groups may relate to a lower blood pressure favoring one group. The trial showed that blood pressure was decreased equally in both groups although not as much as the Captopril Study Group (CSG) ( $\sim 3 \mathrm{mmHg}$ in AMADEO versus $\sim 4 \mathrm{mmHg}$ in CSG). In addition, the telmisartan group separated itself from the losartan group at day 56 by $4.2 \mathrm{mmHg}$, although this difference was narrower at all other time-points. In the context that the study may be underpowered to detect differences in BP between groups, the authors concluded that the blood pressure differences were not statistically significant and larger well-designed trials were needed to detect the effects of such small blood pressure differences on proteinuria. An important observation is that both the treatment arms did not have significant side effects but there was a $20 \%$ dropout rate for the trial which was consistent in both the arms. Clarification regarding the reasons for the dropouts was not outlined in the published trial and could be important in the final analysis. Another factor that could have affected proteinuria is a disproportionate increase in dietary sodium intake in one group, since this is known to blunt the antiproteinuric effects of the ARB. However, the study detected no differences between groups in sodium excretion.

Analysis of the secondary endpoints of AMADEO trial brings forth an interesting trend. Serum aldosterone is an important part of RAAS and evidence points to some of the downstream effects of Ang II are mediated via release of aldosterone. Although not statistically significant, the study detected a trend towards greater reductions in aldosterone in the telmisartan group when compared to the losartan group $(p=0.07)$. The significance of this interesting trend is not clear at this point. However, future studies aimed at dissecting the role of telmisartan in ameliorating aldosteronemediated DKD may answer this question.

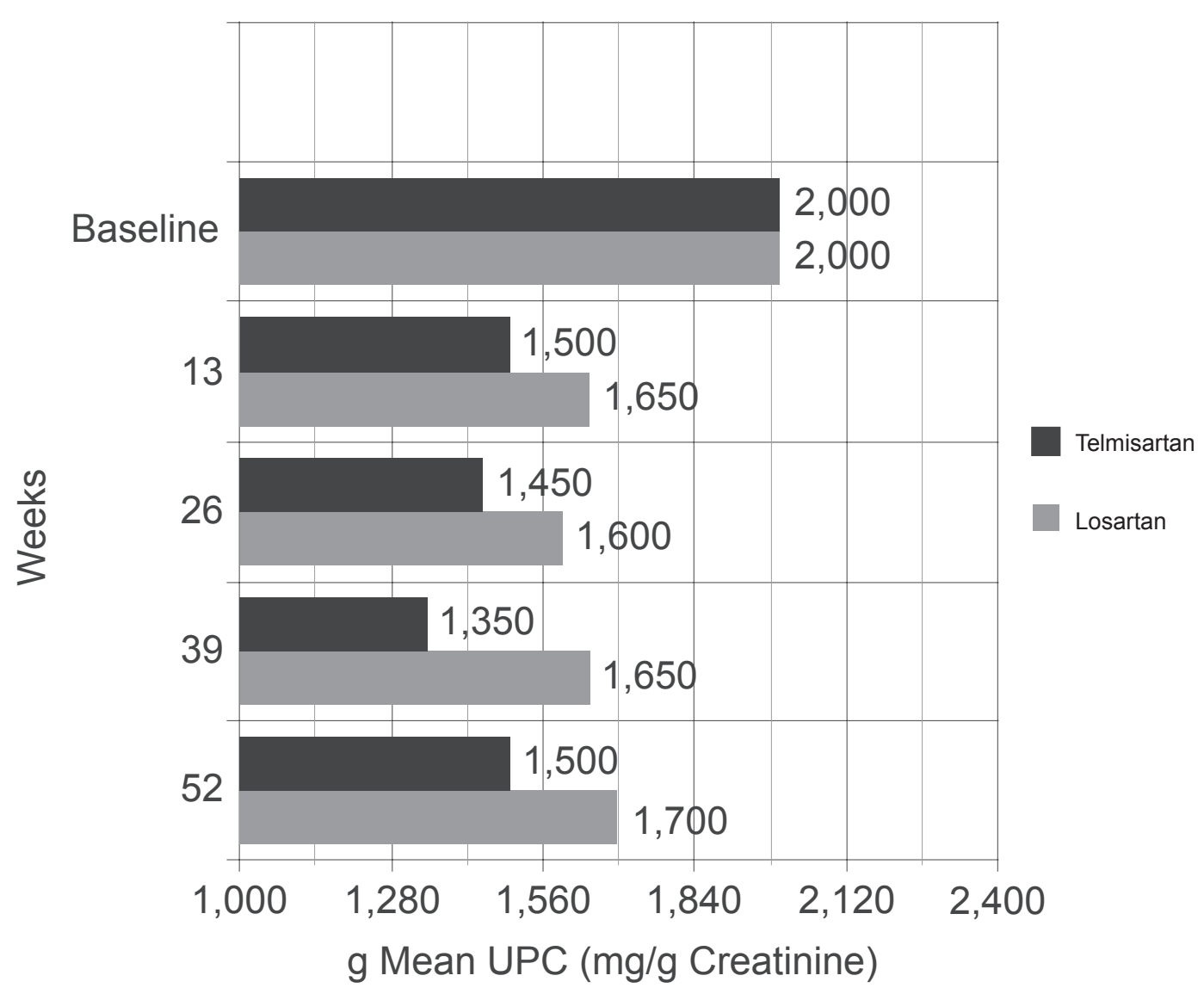

Figure 3 Primary endpoint from AMADEO trial. Patients in the two treatment groups (telmisartan vs losartan) started with the same mean UPC of 2000 mg/g creatinine. Note that the telmisartan arm had significantly lower mean UPC at every time-point over the course of the next year when compared to losartan treated patients. Drawn from data of. ${ }^{2}$ 
Recent data from the VIVALDI trial (as described above) compared the renoprotective effects of telmisartan versus valsartan and found that they had comparable renoprotective effects. ${ }^{31}$ In other words, telmisartan was shown to be non-inferior at best to valsartan in slowing the progression of DKD. These findings were in contrast to the findings of the AMADEO trial. There are several possible explanations for the discrepant results including the methodology used to measure the primary endpoint; urine protein to creatinine ratio in the AMADEO trial as compared to a 24-hour urine protein used in VIVALDI trial. Furthermore, in the VIVALDI trial, participants in the valsartan group required additional antihypertensives more frequently than the telmisartan group to achieve similar levels of blood pressure control. As described above, this important confounding factor was eliminated in the AMADEO trial where none of the treatment arms was favored with better blood pressure control. ${ }^{2}$ Lastly, the ethnicity of the participants in the VIVALDI trial was $80 \%$ Caucasian population compared to just $45 \%$ in the AMADEO trial, the implications of this ethnic homogeneity in VIVALDI with respect to final analysis, are unclear.

\section{Role for aldosterone antagonism}

An important question that arises out of AMADEO trial is the use of aldosterone inhibiting agents to decrease proteinuria? Whole animal studies have suggested that aldosterone may contribute to oxidative stress, endothelial dysfunction and progressive kidney disease. Thereby, administration of selective and non-selective MR antagonists may provide additional renal benefits to the ACE inhibitors and ARBs ${ }^{47}$ In a study published in 2004, Zhou et al showed that spironolactone may effectively reduce proteinuria in patients with CKD. ${ }^{47}$ Concerns remain with regard to the risk for hyperkalemia in patients with CKD, however. Prospective randomized trials are necessary to confirm the efficacy and safety of antagonists of aldosterone on proteinuria and progression of CKD.

\section{Conclusions}

Data from the AMADEO trial demonstrate the superiority and/or non-inferiority of telmisartan as a renoprotective agent when compared to losartan, an already established ARB in the treatment of DKD. The superiority as outlined is based on the unique mechanism of action of this $\mathrm{ARB}$ and the pharmacokinetics which seem to be extremely favorable and ideal for treating DKD. As data from recent clinical trials are emerging, use of proteinuria as a surrogate marker of renal protection is being strongly questioned. However, until additional means of measuring kidney damage on a large scale are available, this endpoint may not have been meaningfully tested. Additional questions arise due to some confounding factors in this study but the overwhelming evidence does uphold the superiority of telmisartan. Lastly, the secondary endpoint of the study does suggest a renoprotective role for aldosterone in DKD and we need well-designed randomized trials for aldosterone antagonists like spironolactone.

\section{Disclosures}

The authors have no conflicts of interest to disclose.

\section{References}

1. American Diabetes Association. Standards of Medical Care in Diabetes. Diabetes Care. 2008;31:S12-S54.

2. Bakris G, Burgess E, Weir M, et al. Telmisartan is more effective than losartan in reducing proteinuria in patients with diabetic nephropathy. Kidney Int. 2008;74(3):364-369.

3. CDC. National Diabetes Fact Sheet. 2007.

4. Dronavalli S, Duka I, Bakris G, et al. The pathogenesis of diabetic nephropathy. Nat Clin Pract Endocrinol Metab. 2008;4:444-452.

5. Vestra M, Saller A, Fioretto P, et al. Role of mesangial expansion in the pathogenesis of diabetic nephropathy. J Nephrol. 2001;14(4): S51-S57.

6. Ziyadeh FN, Wolf G. Pathogenesis of the podocytopathy and proteinuria in diabetic glomerulopathy. Current Diabetes Reviews. 2008;4(1):39-45.

7. Langham RG, Kelly D, Cox A, et al. Proteinuria and the expression of the podocyte slit diaphragm protein, nephrin, in diabetic nephropathy: effects of angiotensin converting enzyme inhibition. Diabetologia. 2002;45(11):1572-1576.

8. Re RN. Mechanisms of disease: local renin angiotensin aldosterone systems and the pathogenesis and treatment of cardiovascular disease. Nat Clin Pract Cardiovasc Med. 2004;1(1):42-47.

9. Hauser AC, Hörl WH. Angiotensin II type-1-receptor antagonists from the viewpoint of nephrology. Journal Wien Med Wochenschr. 2001;151(7-8):160-164.

10. National Kidney Foundation, KDOQI Clinical Practice Guidelines and Clinical Practice Recommendations for Diabetes and Chronic Kidney Disease. Am J Kidney Dis. 2007;49(2 Suppl 2):S12-S154.

11. Hoffmann S, Podlich D, Hähnel B, et al. Angiotensin II type 1 receptor overexpression in podocytes induces glomerulosclerosis in transgenic rats. J Am Soc Nephrol. 2004;15(6):1475-1487.

12. Shibata S, Nagase M, Yoshida S, et al. Podocyte as the target for aldosterone: roles of oxidative stress and Sgk1. Hypertension. 2007;49(2):355-364.

13. Parving HH, Persson F, Lewis JB, et al. AVOID Study Investigators. Aliskiren combined with losartan in type 2 diabetes and nephropathy. N Engl J Med. 2008;358(23):2433-2446.

14. Cortinovis $M$, Cattaneo D, Perico N, et al. Investigational drugs for diabetic nephropathy. Expert Opin Investig Drugs. 2008;17(10):1487-1500.

15. Nistala R, Whaley-Connell A, Sowers JR. Redox control of renal function and hypertension. Antioxid Redox Signal. 2008;10(12):2047-2089.

16. Ruilope L, Jakobsen A, Heroys J, et al. Prospects for renovascular protection by more aggressive renin-angiotensin system control. Medscape J Med. 2008;10(Suppl):S5.

17. Galle J. Reduction of proteinuria with angiotensin receptor blockers Nat Clin Pract Cardiovasc Med. 2008;(5 Suppl 1):S36-S43.

18. Chobanian A, Bakris G, Black H, et al. The Seventh Report of the Joint National Committee on Prevention, Detection, Evaluation, and Treatment of High Blood Pressure. Hypertension. 2003;42:1206-1252. 
19. Yusuf S, Sleight P, Pogue J, et al. Effects of an angiotensin-convertingenzyme inhibitor, ramipril, on cardiovascular events in high-risk patients. The Heart Outcomes Prevention Evaluation Study Investigators. N Engl J Med. 2000;342(3):145-153.

20. Rodby R, Rohde R, Lewis E, et al. The Irbesartan Type II Diabetic Nephropathy Trial. Nephrol Dial Transplant. 2000;15:487-497.

21. Lewis EJ, Hunsicker LG, Clarke WR, et al. Collaborative Study Group. Renoprotective effect of the angiotensin-receptor antagonist irbesartan in patients with nephropathy due to type 2 diabetes. $N$ Engl J Med. 2001;345(12):851-860.

22. Parving H, Lehnert H, Arner P, et al. Irbesartan in Patients with Type 2 Diabetes and Microalbuminuria Study Group The effect of irbesartan on the development of diabetic nephropathy in patients with type 2 diabetes. N Engl J Med. 2001;345(12):870-878.

23. Brenner B, Cooper M, Zeeuw D, et al. RENAAL Study Investigators. Losartan in patients with type 2 diabetes and proteinuria: Observations from the RENAAL Study. N Engl J Med. 2001;345(12):861-869.

24. De Zeeuw D, Remuzzi G, Parving H, et al. Proteinuria, a target for renoprotection in patients with type 2 diabetic nephropathy: lessons from RENAAL. Kidney Int. 2004;65(6):2309-2320.

25. Viberti G, Wheeldon NM, et al. MicroAlbuminuria Reduction With VALsartan (MARVAL) Study Investigators. Microalbuminuria reduction with valsartan in patients with type 2 diabetes mellitus: a blood pressure-independent effect. Circulation. 2002;106:672-678.

26. Ruggenenti P, Fassi A, Ilieva A, et al. Nephrologic Diabetes Complications Trial (BENEDICT) Investigators. Preventing microalbuminuria in type 2 diabetes. $N$ Engl J Med. 2004;351(19):1941-1951.

27. Remuzzi G, Macia M, Ruggenenti P, et al. Prevention and treatment of diabetic renal disease in type 2 diabetes: the BENEDICT study. $\mathrm{J} \mathrm{Am}$ Soc Nephrol. 2006;17(4 Suppl 2):S90-S97.

28. Mann JF, Schmieder RE, McQueen M, et al. Renal outcomes with telmisartan, ramipril, or both, in people at high vascular risk (the ONTARGET study): a multicentre, randomized, double-blind, controlled trial. Lancet. 2008;372(9638):547-553.

29. Barnett AH, Bain SC, Bouter P, et al. Diabetics Exposed to Telmisartan and Enalapril Study Group. Angiotensin-receptor blockade versus converting-enzyme inhibition in type 2 diabetes and nephropathy. N Engl J Med. 2004;351(19):1952-1961.

30. Schmieder R, Delles C, Mimran A, et al. Impact of telmisartan versus ramipril on renal endothelial function in patients with hypertension and type 2 diabetes. Diabetes Care. 2007;30:1351-1356.

31. Galle J, Schwedhelm E, Pinnetti S, et al. VIVALDI investigators. Antiproteinuric effects of angiotensin receptor blockers: telmisartan versus valsartan in hypertensive patients with type 2 diabetes mellitus and overt nephropathy. Nephrol Dial Transplant. 2008; 23(10):3174-3183.

32. Makino H, Haneda M, Babazono T, et al. The Telmisartan Renoprotective Study from Incipient Nephropathy to Overt Nephropathy Rationale, Study Design, Treatment Plan and Baseline Characteristics of the Incipient to Overt: Angiotensin II Receptor Blocker, Telmisartan, Investigation on Type 2 Diabetic Nephropathy (INNOVATION) Study. J Int Med Res. 2005;33:677-686.
33. Yusuf S, Teo K, Pogue J, et al. Telmisartan, ramipril, or both in patients at high risk for vascular events. $N$ Engl J Med. 2008;358(15):1547-59.

34. Hollenberg NK, Parving HH, Viberti G, et al. Albuminuria response to very high-dose valsartan in type 2 diabetes mellitus. $J$ Hypertens. 2007;25(9):1921-1926.

35. Rossing K, Schjoedt KJ, Parving H, et al. Enhanced renoprotective effects of ultrahigh doses of irbesartan in patients with type 2 diabetes and microalbuminuria. Kidney Int. 2005;68(3):1190-1198.

36. Benson SC, Pershadsingh $\mathrm{H}$, Ho C, et al. Identification of telmisartan as a unique angiotensin II receptor antagonist with selective PPAR $\gamma$ modulating activity. Hypertension. 2004;43:993-1002.

37. Wienen W, Hauel N, Van Meel J, et al. Pharmacological characterization of the novel nonpeptide angiotensin II receptor antagonist, BIBR 277. Br J Pharmacol. 1993;110(1):245-252.

38. Wolfgang W, Entzeroth M, Stangier J, et al. A review on telmisartan: a novel, long-acting angiotensin II-receptor. Cardiovasc Drug Rev. 2006;18(2):127-154.

39. Kakuta H, Sudoh K, Sasamata M, et al. Telmisartan has the strongest binding affinity to angiotensin II type 1 receptor: comparison with other angiotensin II type 1 receptor blockers. Int J Clin Pharmacol Re. 2005;25(1):41-46.

40. Panchapakesan U, Pollock C, X Chen, et al. PPAR gamma agonists exert antifibrotic effects in renal tubular cells exposed to high glucose. Am J Physiol Renal Physiol. 2005;289:F1153-F1158.

41. Guan Y, Hao C, Cha DR, et al. Thiazolidinediones expand body fluid volume through PPARgamma stimulation of ENaC-mediated renal salt absorption. Nat Med. 2005;11(8):861-866.

42. Yang T, Soodvilai S. Renal and vascular mechanisms of thiazolidinedione-induced fluid retention. PPAR Research. 2008;943614: doi:10.1155.

43. Schupp M, Clemenz M, Gineste R, et al. Molecular characterization of new selective peroxisome proliferator-activated receptor gamma modulators with angiotensin receptor blocking activity. Diabetes. 2005;54(12):3442-3452.

44. Zhang $\mathrm{H}$, Zhang A, Kohan DE, et al. Collecting duct-specific deletion of peroxisome proliferator-activated receptor $\gamma$ blocks thiazolidinedione-induced fluid retention. Proc Natl Acad Sci U S A. 2005;102(26):9406-9411.

45. Rubenstrunk A, Hanf R, Hum D, et al. Safety issues and prospects for future generations of PPAR modulators. Biochim Biophys Acta. 2007;1771(8):1065-1081.

46. Zhang F, Lavan B, Gregoire F, et al. Selective modulators of PPAR- $\gamma$ activity: molecular aspects related to obesity and side-effects. PPAR Res. 2007;32696:doi:10.1155.

47. Zhou X, Ono H, Frohlich E, et al. Aldosterone antagonism ameliorates proteinuria and nephrosclerosis independent of glomerular dynamics. Am J Nephrol. 2004;24:242-249.

48. Makino H, Haneda M, Babazono T, et al. Prevention of transition from incipient to overt nephropathy with telmisartan in patients with type 2 diabetes. Diabetes Care. 2007;30:1577-1578. 